\title{
Estudos sobre a vegetação das Campinas Amazonicas - III A vegetação lenhosa da Campina da Reserva Biológica INPA - SUFRAMA (Manaus - Caracarai, km 62)
}

\author{
Arthony B. Anderson \\ Ghillean T. Prance (') \\ Byron W. P. de Albuquerqus $\left.{ }^{2}\right]$
}

\section{Resumo}

Na Amazônia, na região do rio Negro, os solos de areia branca dispersos com sua vegetação associada, conhecida como campina amazônica, podem ter influência considerável sobre a ecologia total dos sistemas de rios de água preta. Este trabalho apresenta uma descrição da vegetação lenhosa de uma campina amazônica e de sua campinarana associada.

Para que essa vegetação seja melhor interpretada, os autores opinam em considerá-la dividida em dois tipos: campina e campinarana. A campinarana, por sua vez, é subdividida em dois subtipos: campina aberta e campina sombreada. A estrutura e a composição da vegetação de cada tipo ou subtipo foram estudadas com detalhes. Com base no testemunho de sua vegetação, os autores concluem que a campinarana representa uma vegetação em clímax.

\section{INTRODUÇÃo}

Recentemente tem sido dada atenção aos solos tropicais de areia branca, principalmente aqueles encontrados dispersos pela região do rio Negro na Amazônia. Tais solos foram descritos de maneira variada como "podzóis tropicais de terras baixas" ("lowland tropical podzols") (Richards, 1941) e "regossóis" (Falesi et al., 1971). Klinge (1967) salienta que a água filtrada desses solos é fonte dos rios de água preta da Amazônia, com deficiência de nutrientes minerais e biologicamente empobreci. dos. Janzen (1974) diz que a vegetação sobre tais solos pode conter altas concentrações de substâncias secundárias tóxicos que são lixiviadas para os rios de água preta: isto poderia pelo menos firnecer uma explicação parcial pa. a a "extrema pobreza biológica desses rios. Que esta hipótese de Janzen prove ser ou não correta, parece-nos que os solos de areia branca e sua vegetação associada desempenham imporiante papel em toda a ecologia dos sistemas dos rios de água preta da Amazônia.

Existem poucas referências na literatura a respeito das campinas amazônicas, uma vegetação característica de solos de areia branca no norte da Amazônia, especialmente na região do rio Negro. Richards (1952) relaciona as campinas com outros tipos de vegetação que ocorrem sobre areias brancas nas terras baixas tropicais de toda parte do mundo, como por exemplo o "urzal" e as "Kerangas" da Austrália, a mata de "wallaba" (Eperua sp.) da Guiana, e o matagal de "muri" (muri bush) do norte da América do Sul. A característica mais notável, comum a todos esses tipos de vegeiaçäo, é a tendência de uma ou poucas espécies dominarem sobre as demais. A vegetaçäo relativamente empobrecida das campinas amazônicas, da região do rio Negro, contrasta claramente com a mata de terra firme que as circunda, a qual é caracterizada por uma diversidade alta de espécies (Prance et alii, no prelo) . As campinas amazônicas são também bastante características em relação à sua estrutura vegetacional. Enquanto a mata de terra firme se caracteriza por árvores altas formando um dossel virtualmente fechado, a vegetação das campinas é baixa e com muitas manchas abertas. Em vista aérea, as campinas podem ser perfeitamente distinguidas, aparecendo como pequenas ilhas dispersas no oceano da floresta amazônica.

Além das cbservações de Ducke \& Black (1954) e os estudos feitos por Takeuchi (1960)

(1) - B.A. Krukoff Curator of Amazonian Botany, The New York Botanical Garden.

(2) - Instituto Nacional de Pesquisas da Amazônia, Manaus. 
e outros, nada mais foi publicado fornecendo uma descrição detalhada da vegetação de uma campina. Lisbôa (1975) apresenta uma revisão completa da literatura sobre campinas amazônicas. Talvez a falta de estudos anteriores tenha resultado em uma confusão na nomenclatura das campinas da região do rio $\mathrm{Ne}$ gro. Esta confusão aumenta com o uso dos termos "caatingas" para as campinas do alto rio Negro (Spruce, 1908; Rodrigues, 1964). Lisbôa (1975) resolve esta confusão discutindo com alguns detalhes as características que distinguem as campinas amazônicas das caatingas da região nordeste do Brasil. Seguindo a revisão de Lisbôa, procuramos dar um esclarecimento detalhado da estrutura e da composição da vegetação lenhosa de uma campina amazônica, a fim de reduzir esta confusão e formar assim uma base para pesquisas futuras. Além disso, examinamos estes aspectos dentro de outro tipo de vegetação relacionado com a campina, conhecido como campinarana - campina + rana (sufixo da língua indígena local) $=$ falsa campina.

A área estudada está localizada dentro da Reserva Biológica de Campina INPA-SUFRAMA (Instituto Nacional de Pesquisas da Amazônia e Superintendência da Zona Franca de Manaus), estrada Manaus-Caracaraí, km 62, Amazonas, Brasil. Para fins de discussão, esta campina é ocasionalmente referida no texto como "Reserva de Campina".

\section{MÉTodos E RESUltados}

Um problema de imediato para se estudar uma vegetação, é determinar a dimensão de uma área necessária para se obter uma amos. tragem representativa dessa vegetação. A fi. gura 1 ilustra o aumento do número de espécies lenhosas em relação ao aumento de área dentro da vegetação da campina, de acordo com Takeuchi (1960). O número de espécies nivela-se em 24 quando uma área de amostragem de 175 a $200 \mathrm{~m}^{2}$ é atingida. Takeuchi conclui que essa área deveria ser suficiente para fornecer uma amostragem significativa da vegetação lenhosa de uma campina.

Para estarmos certos de ter obtido representação precisa, tiramos uma amostragem da vegetação da Reserva de Campina de uma área muito maior do que aquela recomendada por Takeuchi (1960), isto é, fizemos três parcelas de $10 \times 10 \mathrm{~m}, 15 \times 15 \mathrm{~m}$ e $20 \times 20 \mathrm{~m}$ na campina, totalizando uma área de $725 \mathrm{~m}^{2}$. $\mathrm{Na}$ campinarana estudamos apenas uma parcela de $15 \times 15 \mathrm{~m}\left(225 \mathrm{~m}^{2}\right)$. Dentro dessas parcelas coritamos todas as espécies lenhosas, medimos seus diâmetros e mapeamos todos os individuos com diâmetro acima de $1 \mathrm{~cm}$. Em alguns casos era impossível distinguir plântulas das espécies intimamente aparentadas. Por este motivo não fizemos qualquer distinção entre Clusia aff. columnaris Engl. e Clusia of. nemorosa G. F. W. Meyer (Guttiferae), nem entre Matayba opaca Radlk. e Talisia cesarina (Benth.) Radlk. (Sapindaceae), dentro das parcelas amostradas. A figura 7 , mostra as freqüências relativas e as áreas basais das espécies lenhosas dominantes da campina e da campinarana (mais explicações são encontradas na Discussão).

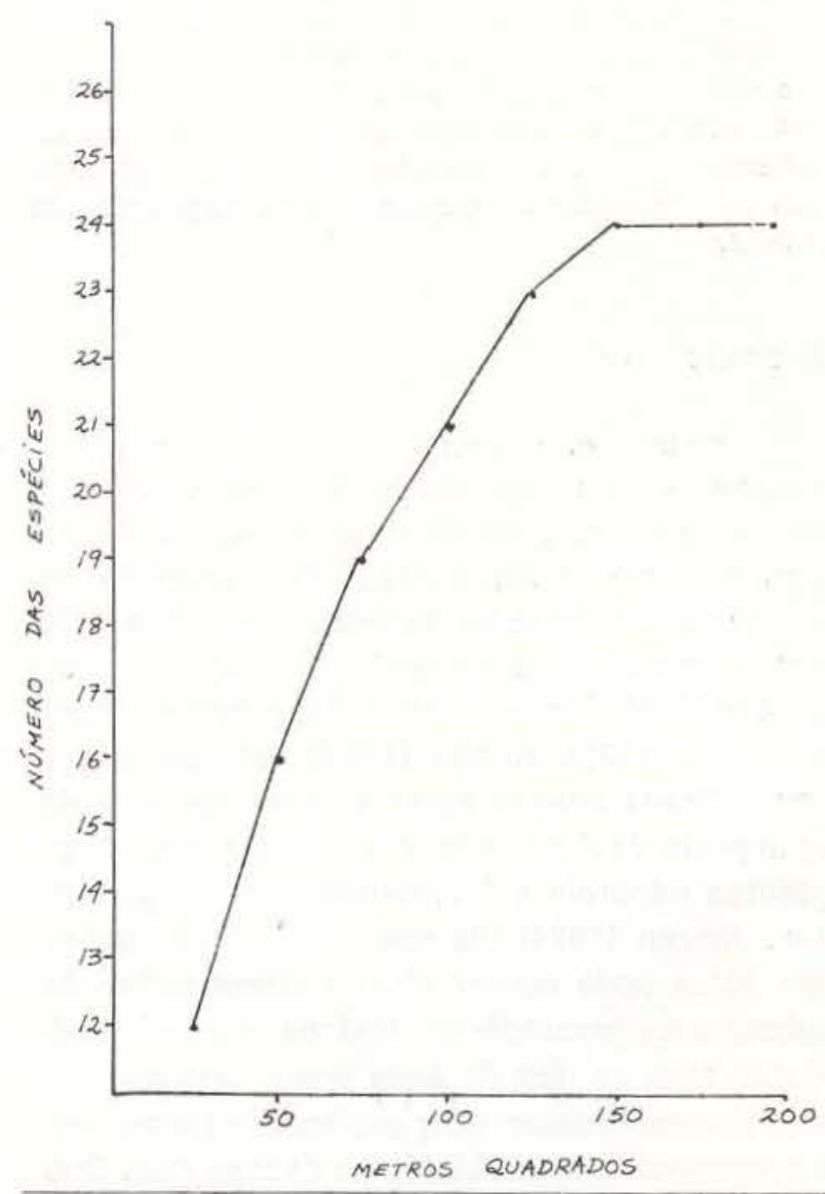

Fig. 1 - Aumento em número das espécies lenhosas em relação ao aumento de área na campina. (Adaptada de Takeuchi (1960).) 


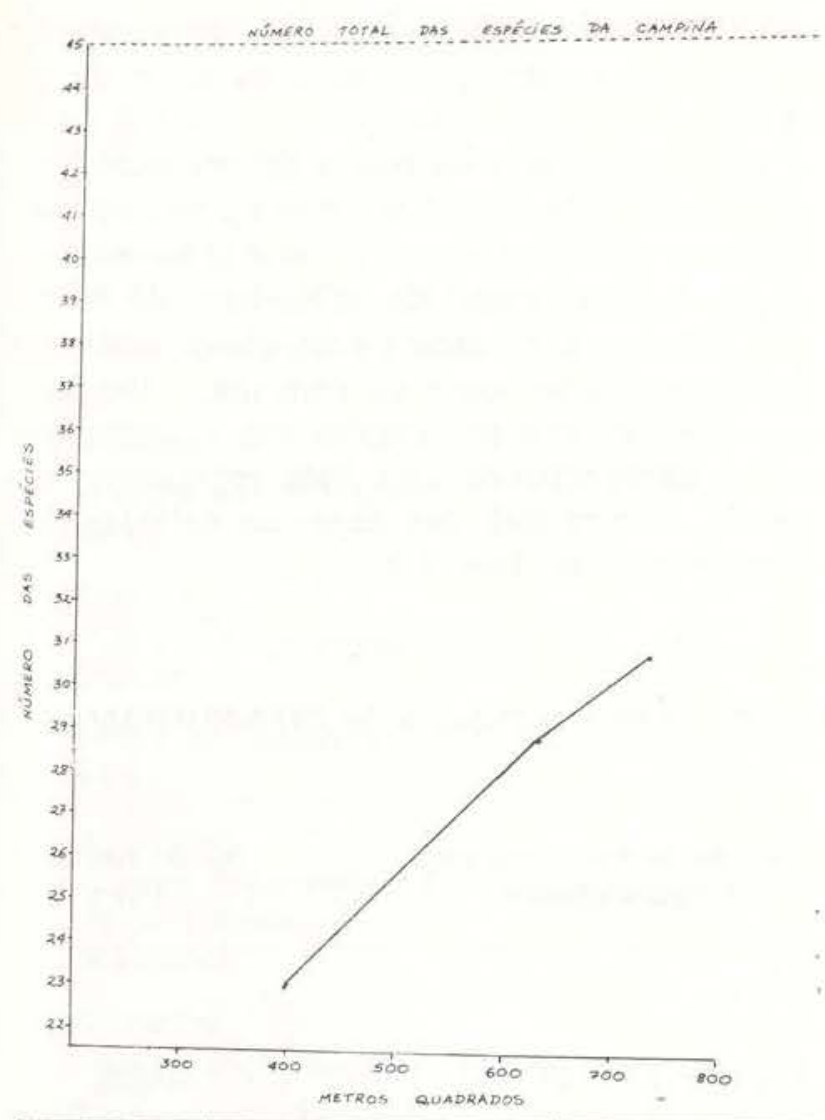

Fig. 2 - Aumento em número das espécies lenhosas em relação ao aumento de área na campina da Reserva Biológica do INPA-SUFRAMA.

A figura 2 mostra um gráfico semelhante ao de Takeuchi (1960) baseado em nossos resultados. Aqui, o número de espécies lenhosas é de 31 e ainda continua crescendo numa área de amostragem de $725 \mathrm{~m}^{2}$. Isto evidencia um aspecto interessante da vegetação da cam. pina, que Takeuchi não descreveu. Embora relativamente pobre, a vegetação de uma campina não é uniforme, apresentando considerável variação de lugar para lugar ,na mesma campina. As espécies tendem a se concentrar em grupos, em áreas largamente dispersas. Por exemplo, na Reserva de Campina, Humiria balsamifera St. Hil. var. floribunda (Mart.) Cuatr., ocorre em manchas em alta concentração, e dentro destes grupos poder-se-ia concluir que esta espécie é dominante na vegetação da cam- pina. Contudo, um levantamento completo aa campina revelou que as concentrações de $H$. balsamifera var. floribunda são muito dispersas. De fato, ela ocorre apenas ocasional. mente. O mesmo fenômeno se dá com outras espécies, como Manilkara amazonica (Huber) Standl.

É evidente que uma área grande de campina deve ser estudada, a fim de obter uma amostragem representativa de seu conteúdo em espécies. Mas com exceção apenas de Phthirusa rufa (Mart.) Eichl. (uma hemiparasita ocasional não encontrada nas parcelas amostradas, mas estudadas no trabalho de Braga \& Braga, 1975, a seguir), todas as espécies lenhosas ausentes das parcelas estudadas por nós são raras dentro da Reserva de Campina. Ademais, para as finalidades de nosso estudo, as parcelas de amostragem são um meio muito importante para determinar as freqüências relativas, as áreas basais e as relações fitossociológicas das espécies dominantes.

Neste trabalho definimos as dominantes da campina e da campinarana como espécies que apresentam um grau de importância $\left({ }^{3}\right)$ maior do que, ou igual a $5 \%$, dentro das áreas de amostragem. Confiamos que as três parcelas estudadas na campina, abrangendo uma área total de $725 \mathrm{~m}^{2}$, sejam suficientes para fornecer uma amostragem raozavelmente significativa. Para testarmos isto, calculamos o grau de importância da principal espécie dominante de campina, Glycoxylon inophyllum (Mart. ex Miq.) Ducke, na área total amostracla $\left(725 \mathrm{~m}^{2}\right)$. Em seguida, este valor foi comparado com o valor derivado da área analisada sem a parcela de $15 \times 15 \mathrm{~m}$, ou da área total de amostragem de $500 \mathrm{~m}^{2}$. Nesta última o grau de importância de $G$. inophyllum foi de $31,4 \%$, comparado ao de $32,4 \%$ na área de $725 \mathrm{~m}^{2}$. Esta ligeira variação no grau de importância indica que, quanto à espécie dominante mais importante da campina, a área de $725 \mathrm{~m}^{2}$ é mais do que suficiente para fornecer uma amostragem representativa. 
Além dos processos para obtenção de amostragem da vegetação anteriormente esboçados, realizamos um inventário das espécies lenhosas existentes na campina da Reserva de Campina. Nesta, foram feitas coletas de material botânico durante um período de 4 anos, o qual se encontra depositado no Herbário do INPA. Ademais, recentemente, fizemos um esforço intensivo para colher amostras das espécies lenhosas que ocorrem na campina. Como resultado deste trabalho, apresentamos uma lista das espécies lenhosas na Tabela I, que possivelmente está completa. A freqüên- cia de cada espécie incluída foi baseada em observações feitas pelo principal autor deste trabalho em toda a campina. Citamos pelo menos um número de coleta de um exemplar de cada espécie para servir como prova ou tesŁemunho deste trabalho. O espécime correspondente está depositado no Herbário do INPA.

O Anexo 1 apresenta uma chave analitica das espécies lenhosas da campina. Realizamos mais coletas na campinarana e, baseados nelas, apresentamos uma lista representativa (ainda incompleta) das espécies colhidas na campinarana, na Tabela 2.

Tabela 1. Lista das espécies lenhosas na campina da Reserva Biológica do INPA-SUFRAMA.

Familia e espécie
N. do herbário campina para citação
N.॰ de Registro INPA

\section{Annonaceae}

Annona nitida Mart. Ocasional.

Léa Carreira 28

Apocynaceae

Mandevilla ulei K. Schum.

Albuquerque 1099

48650

Comum.

Albuquerque 1102

48653

Comum.

Burseraceae

Protium heptaphyllum (Aubl.) March.

Comum.

Léa Carreira 34

48812

Chrysobalanaceae

Hirtella racemosa Lam. var. racemosá

Prance et al 13336

Comum

Léa Carreira 29

48807

Mikania roraimensis Robinson

Ocasional.

Vernonia grisea Baker

Léa Carreira 33

Ocasional.

Doliocarpus spraguei Cheesm. Ocasional.

Erythroxylaceae

Erythroxylom sp.

Anderson 45

48787

Rara.

Euphorbiaceae

Mabea occidentalis Benth.

Léa Carreira 30

48808

Comum. 
Tabela 1. Lista das espécies lenhosas... (continuação)

\section{Gesneriaceae}

Codonanthe sp.

P.I.S. Braga 2928

49725

Rara.

Codonanthe aff. crassifolia (Focke) Morton

Anderson 53

48789

Rara.

Codonanthopsis aggregata (Mart.) Hoehne

Prance et al 11324

29724 Rara.

Gnetaceae

Gnetum paniculatum Spr.

Rara.

Silva e Coêlho 52

35186

Guttiferae

Clusia aff. columnaris Engl.

Comum.

Clusia cf. nemorosa G.F.W. Meyer Rara.

Silva e Coêlho 55

35189

Léa Carreira 22

48802

Humiriaceae

Humiria balsamifera St. Hil. var floribunda

Prance et al 13340

31704

(Mart.) Cuatr.

Ocasional.

Icacinaceae

Dendrobangia sp.

Rara.

Anderson 68

48788

Leguminosae

Aldina heterophylla Spr. ex Benth

Ocasional.

Macrolobium arenarium Ducke

(Estéril.)

Anderson 57

48879

(Estéril.)

Rara.

Léa Carreira 36

48813

Ormosia costulata (Miq.) Kleinh.

Ocasional.

Albuquerque 1097

48648

Swartzia dolicopoda Cowan

Ocasional.

Albuquerque 1079

48630

Anderson 52

48791

Loranthaceae

Phthirusa micrantha Eichl.

Léa Carreira 31

48809

Ocasional.

Phthirusa rufa (Mart.) Eichl.

Léa Carreira 26

48804

Ocasional.

Malpighiaceae

Heteropterys aff. acutifolia Adr. Juss.

Rara.

M. Macedo 4A

48496

Melastomataceae

Sandemania hoehnei (Cogn.) Wurdack

Comum.

Miconia lepidota DC.

Ocasional.

Mouriri nervosa Pilg.

Rara.

Léa Carreira 27

48805

Anderson 64

48868

(Estéril.)

Albuquerque 1089

48640

Estudos sobre a vegetação... 
Tabela 1. Lista das espécies lenhosas... (continuação)

Myrsinaceae

Conomorpha cf. grandiflora $\mathrm{Mez}$

Comum.

Albuquerque 1069

48620

Myrtaceae

Eugenia patrisii Vahl

Prance et al 11352

29752

Rara.

Albuquerque 1111

48662

Comum.

Myrcia servata McVaugh

Rara.

Prance et al 11353

29753

Ochnaceae

Ouratea spruceana Engl.

Comum.

Léa Carreira 32

48810

Passifloraceae

Passiflora faroana Harms

Anderson 49

48792

Ocssional.

Rubiaceae

Borreria capitata var. tenella (H.B.K.) Steyerm.

Ocasional.

?Duroia sp.

Rara.

Pagamea duckei Standl.

Comum.

Palicourea nitidella (M. Arg.) Standl.

Ocasional.

Psychotria cf. lupulina Benth. subsp. rhodoleuca

(M. Arg.) Steyerm. var. maypurensis (Humb.

\& Bonpl. ex R. \& S.) Steyerm. sensu Steyerm.

Léa Carreira 21

48799

Ocasional.

Psychotria barbiflora DC.

Léa Carreira 25

48803

Rara.

Anderson 62

48794

Sapindaceae

Matayba opaca Radlk.

Anderson 48

48795

Comum.

Talisia cesarina (Benth.) Radlk.

Comum.

Albuquerque 1098

48649

1110

48661

Sapotaceae

Glycoxylon inophyllum (Mart. ex Miq.) Ducke

Léa Carreira 22

48800

Comum.

Manilkara amazonica (Huber) Standl.

Anderson 54

48797

Ocasional.

(Estéril)

Vochysiaceae

Qualea retusa Spr. ex Warm.

Anderson 69

48796

Rara.

Observação: As frequiências são referentes à distribuição na campina somente, não incluindo a campinarana 
Tabela 2. Lista representativa das espécies lenhosas na campinarana da Reserva Biológica do INPA - SUFRAMA.

\begin{tabular}{|c|c|}
\hline Familia & Espécie \\
\hline Anacardiaceae & Tapirira sp. \\
\hline Annonaceae & $\begin{array}{l}\text { Annona nitida Mart. } \\
\text { Anaxagorea sp. } \\
\text { Bocageopsis multiflora (Mart.) R. E. Fries }\end{array}$ \\
\hline Apocynaceae & $\begin{array}{l}\text { Lacmellea ramosissima (Muell. Arg.) Markgraf } \\
\text { Tabernaemontana rupicola Benth. }\end{array}$ \\
\hline Bignoniaceae & Não identificada. \\
\hline Bombacaceae & Scleronema micranthum (Ducke) Ducke \\
\hline Burseraceae & $\begin{array}{l}\text { Protium heptaphyllum (Aubl.) March. } \\
\text { Hemicrepidospermum rhoifolium (Benth.) Swart }\end{array}$ \\
\hline Chrysobalanaceae & $\begin{array}{l}\text { Couepia racemosa Benth. ex Hook. } f . \\
\text { Hirtella racemosa Lam. var. racemosa } \\
\text { Licania lata Macbr. }\end{array}$ \\
\hline Compositae & Mikania roraimensis Robinson \\
\hline Dilleniaceae & Doliocarpus spraguei Cheesm. \\
\hline Ericaceae & Satyria panurensis Benth. \& Hook. f. \\
\hline Erythroxylaceae & Erythroxylom sp. \\
\hline Euphorbiaceae & $\begin{array}{l}\text { Micranda sp. } \\
\text { Nealchornia japurensis Hub. } \\
\text { Pera sp. } \\
\text { Mabea occidentalis Benth. }\end{array}$ \\
\hline Gesneriaceae & $\begin{array}{l}\text { Codonanthe aff. crassifolia (Focke) Morton } \\
\text { Codonanthopsis aggregata (Mart.) Hoehne }\end{array}$ \\
\hline Gnetaceae & Gnetum paniculatum Spr. \\
\hline Guttiferae & $\begin{array}{l}\text { Clusia aff. columnaris Engl. } \\
\text { Clusia cf. nemorosa G. F. W. Meyer } \\
\text { Clusia sp. }\end{array}$ \\
\hline Icacinaceae & Dendrobangia sp. \\
\hline Lauraceae & $\begin{array}{l}\text { Endlicheria arunciflora Mez } \\
\text { Nectandra sp. } \\
\text { Ocotea } \mathrm{sp} .\end{array}$ \\
\hline Lecythidaceae & Couratari sp. \\
\hline Leguminosae & $\begin{array}{l}\text { Aldina heterophylla Spr. ex Benth. } \\
\text { Eperua bijuga Mart. ex Engl. } \\
\text { Machaerium sp. } \\
\text { Mácrolobium arenarium Ducke } \\
\text { Ormosia costulata (Miq.) Kleinh. } \\
\text { Parkia sp. } \\
\text { Swartizia dolicopoda Cowan }\end{array}$ \\
\hline Linnaceae & Roucheria punctata (Ducke) Ducke \\
\hline Loranthaceae & Phthirusa rufa (Mart.) Eichl. \\
\hline Malpighiaceae & Heteropterys aff. acutifolia Adr. Juss. \\
\hline Melastomataceae & $\begin{array}{l}\text { Miconia lepidota DC. } \\
\text { Mouriria nervosa Pilg. }\end{array}$ \\
\hline Meliaceae & Trichilia sp. \\
\hline Moraceae & Ficus sp. \\
\hline Myristicaceae & $\begin{array}{l}\text { Iryanthera lanceifolia Ducke } \\
\text { Virola pavonis (A. DC.) A. C. Sm. }\end{array}$ \\
\hline Myrsinaceae & Conomorpha sp. \\
\hline
\end{tabular}

Estudos sobre a vegetação... 
Tabela 2. Lista representativa das espécies lenhosas... (continuação)

$\begin{array}{ll}\text { Myrtaceae } & \text { Eugenia sp. } \\ & \text { Myrcia servata McVaugh } \\ \text { Ochnaceae } & \text { Ouratea spruceana Engl. } \\ \text { Olacaceae } & \text { Minquartia guianensis Aubl. } \\ \text { Palmae } & \text { Bactris arenaria Barb. Rodr. } \\ & \text { Oenocarpus bataua Mart. } \\ & \text { Mauritia carana Wall. } \\ & \text { Rhaphia vinifera Pal. de Beauv. var. taedigera Ducke } \\ \text { Rubiaceae } & \text { Borreria capitata var. tenella (H. B. K.) Steyerm. } \\ & \text { Duroia sp. } \\ & \text { Ixora warmingii M. Arg. } \\ & \text { Pagamea duckei Standl. } \\ & \text { Palicourea nitidella (M. Arg.) Standl. } \\ & \text { Psychotria barbiflora Radlk. } \\ & \text { Psychotria sp. } \\ & \text { Matayba opaca Radlk. } \\ & \text { Matayba sp. } \\ \text { Salisia cesarina (Benth.) Radlk. } \\ \text { Glycoxylon inophyllum (Mart. ex Miq.) Ducke } \\ \text { Glycoxylon pedicellatum Ducke } \\ \text { Manilkara amazonica (Huber) Standl. } \\ \text { Ragala cf. spuria (Ducke) Aubr. } \\ \text { Simaruba amara Aubl. }\end{array}$

Finalmente, preparamos alguns perfís (Figs. 3 e 5) e mapas basais (Figs. 4 e 6) das parcelas estudadas, a fim de mostrar a fisionomia da vegetação da campina e da campinarana

\section{Discussão}

A área de campina da Reserva de Campina abrange uma área não maior do que alguns hectares de extensăo. Apesar do seu tamanho, esta área apresenta considerável variação em termos de cobertura vegetal, conforme melhor demonstrado nas figuras 3 e 4 . Em alguns lugares há espaços abertos de areia branca, pontilhados com um arquipélago de ilhas pequenas e dispersas de vegetação variável. Esta compõe-se de subarbustos e árvores pequenas; as árvores nunca ultrapassam de $5 \mathrm{~m}$ de altura. O conteúdo destas ilhas é analisado com mais detalhes no trabalho de Braga \& Braga (1975), parte 4 desta série de trabaIhos. Próximo destes espaços relativamente abertos, podem ocorrer ilhas de vegetação maiores e mais densas, dominadas por Glyco-

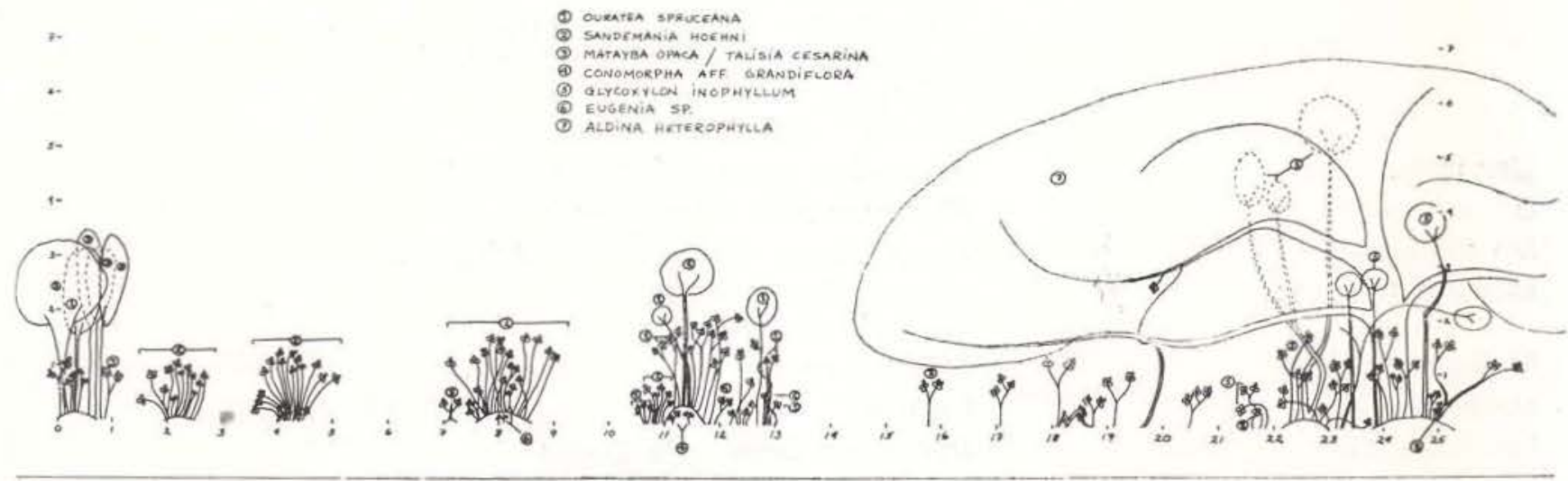

Fig. 3 - Perfil de uma área de $25 \times 2 \mathrm{~m}$ na campina da Reserva Biológica do INPA-SUFRAMA, com indicação das espécies dominantes. 


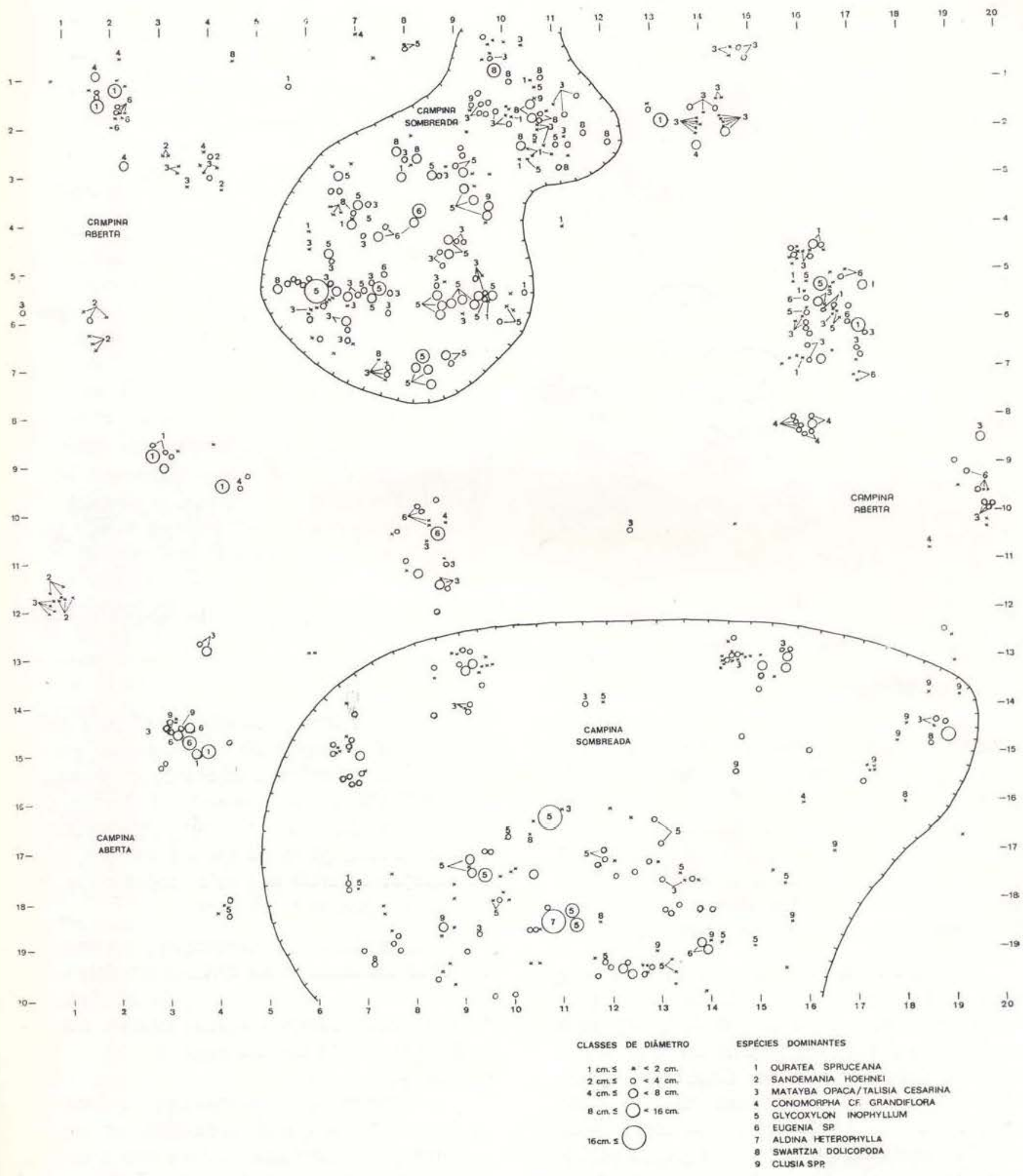

Fig. 4 - Mapa basal de uma área de $20 \times 20 \mathrm{~m}$ na campina da Reserva Biológica do INPA-SUFRAMA, com indicação das espécies dominantes. 


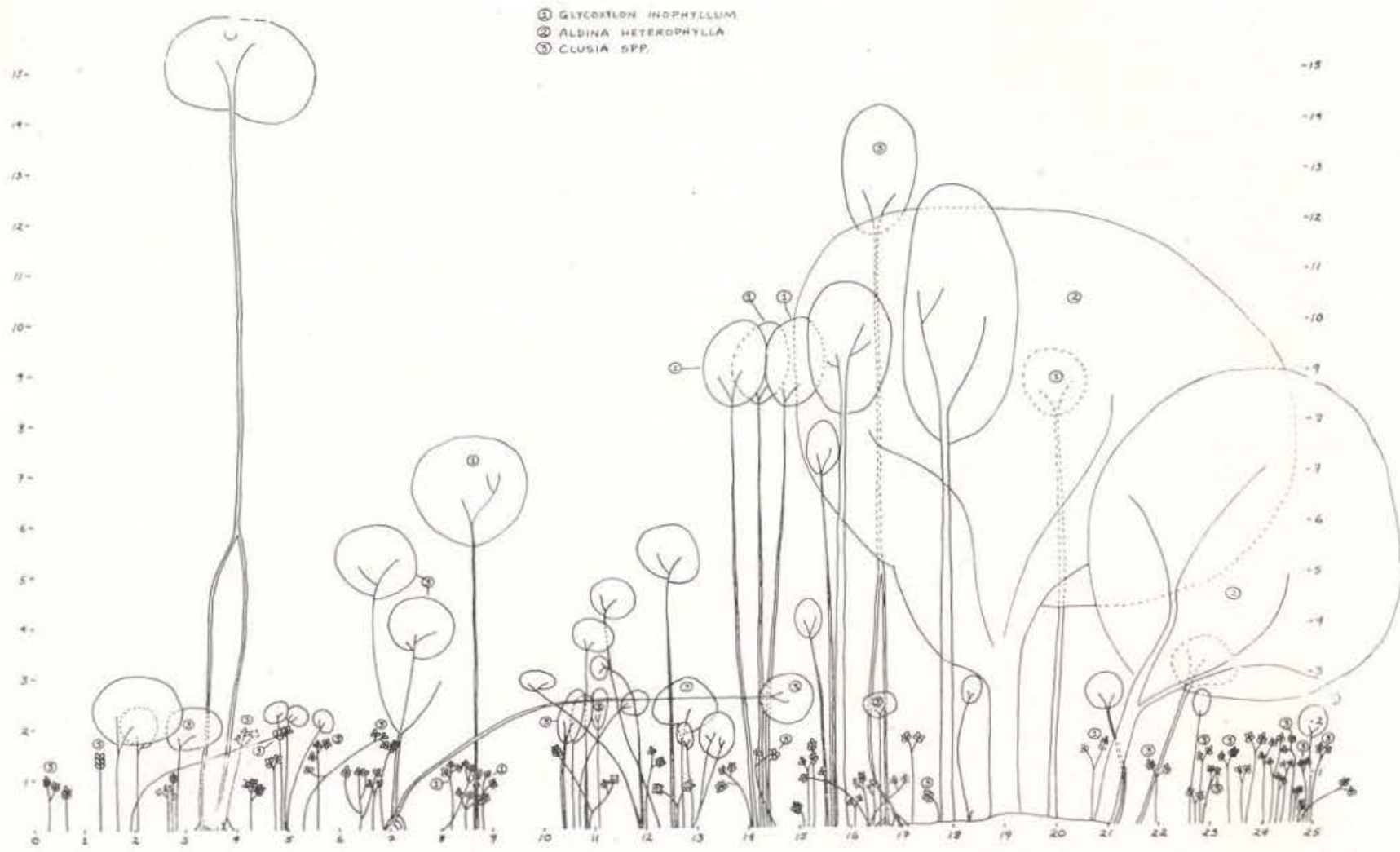

Fig. 5 - Perfil de uma área de $25 \times 2 \mathrm{~m}$ na campinarana da Reserva Biológica do INPA-SUFRAMA, com indicação das espécies dominantes.

xylon inophyllum (Mart. ex Miq.) Ducke, ("casca doce"), e ocasionalmente uma árvore grande de Aldina heterophylla Spr. ex Benth ("macucu"). As árvores destas ilhas maiores podem alcançar $7 \mathrm{~m}$ ou mais de altura. Freqüentemente estas ilhas se misturam com a campinarana circundante, onde as árvores mais altas ultrapassam a $10 \mathrm{~m}$ de altura, formando um dossel mais ou menos contínuo (Figs. 5 e 6).

Embora a vegetação característica da campina e da campinarana forme claramente uma série contínua, é necessário dividí-la em tipos ou subtipos descritivos para melhor e mais claramente desenvolver nossa discussão. Consideramos campina e campinarana dois tipos distintos de vegetação. Definimos como "campina" a vegetação que ocorre em grupos perfeitamente distintos, formando ilhas ou penínsulas, cercadas ou próximas de áreas relativamente abertas em solo arenoso descoberto. As árvores mais altas da campina nunca chegam a atingir $10 \mathrm{~m}$ de altura, e o dossel (onde há) é raramente contínuo sobre uma grande área
Usamos o termo "campinarana" para definir um tipo de vegetação mais contínua sobre solo arenoso, similar e adjacente à campina. $\mathrm{Na}$ campinarana, grupos isolados de árvores de porte mais elevado (algumas ultrapassando $10 \mathrm{~m}$ de altura) podem ainda ser notados, mas os espaços de areia são colonizados pelas árvores mais jovens e arbustos.

Para se discutir a vegetação de campina, achamos conveniente subdividi-la em dois subtipos: campina aberta e campina sombreada. $\mathrm{Na}$ Reserva da Campina, como tentativa, definimos estes termos como a seguir:

A campina aberta compõe-se de ilhas de vegetação em que cada ilha apresenta uma área menor que $1 \mathrm{~m}^{2}$ e sobre a qual a cobertura do dossel é menos de $50 \%$.

A campina sombreada refere-se às ilhas ou áreas de vegetação maiores de $1 \mathrm{~m}^{2}$ sobre a qual a cobertura do dossel ultrapassa $50 \%$. 
Não obstante sejam estas últimas definições um tanto arbitrárias, elas correspondem muito bem às mudanças significativas em estrutura e composição da vegetação quando se caminha de um subtipo para outro; por isto, cmpregamos estes termos na discussão a seguir.

\section{CAMPINA ABERTA}

Nesta, a vegetação tende a ser estruturalmente homogênea. Geralmente ela se compõe de um estrato superior baixo de subarbustos a partir do solo até $2 \mathrm{~m}$ de altura, e um estrato superior de arbustos e árvores pequenas de 2 a $5 \mathrm{~m}$ de altura. Cada estrato é tipicamente composto de uma ou poucas espécies, e cada espécie tende a ser representada por poucos ou muitos indivíduos de idades próximas.

As condições xeromórficas e defıciência de nutrientes minerais predominantes na campinas aberta tornam difícil o estabelecimento no local. De fato, poucas espécies são capazes de colonizar os espaços vazios arenosos. Nestes espaços, os líquens (por exemplo Cladonia sp.) formam uma manta sobre grandes áreas de areia e sua presença é decisiva para o estabelecimento inicial das espécies lenhosas. Ribeiro \& Santos (1975) salientam que, em áreas abertas e arenosas da Reserva da Campina, a temperatura do solo varia $16,7^{\circ} \mathrm{C}$ (de $25,6^{\circ}$ a $42,3^{\circ} \mathrm{C}$ ), ao passo que, sob os liquens a variação é de $8,8^{\circ} \mathrm{C}$ (de $23,6^{\circ}$ a $32,4^{\circ} \mathrm{C}$ ). Obviamente que esta alteração na temperatura do solo é vital para o estabelecimento de plantas lenhosas.

Os colonizadores lenhosos pioneiros da campina aberta são a típica Sandemania hoehnei (Cogn.) Wurdack (ver também Braga \& Braga no próximo trabalho) e, em menor importância, Matayba opaca Radlk., Conomorpha cf. grandiflora Mez e Eugenia sp. Ocasionalmente são encontradas Vernonia grisea Baker e Borreria capitata var. tenella, (H.B.Y.) Steyerm., colonizando os espaços abertos de areia branca. Ilhas pequenas de vegetação estão dispersas por toda a campina aberta, composta inteiramente de indivíduos de mesma idade que representam uma ou outra destas espécies. A figura 3 apresenta diversas ilhas dominadas pela Sandemania hoehnei. Nestas pequenas ilhas, depósitos de matéria orgânica

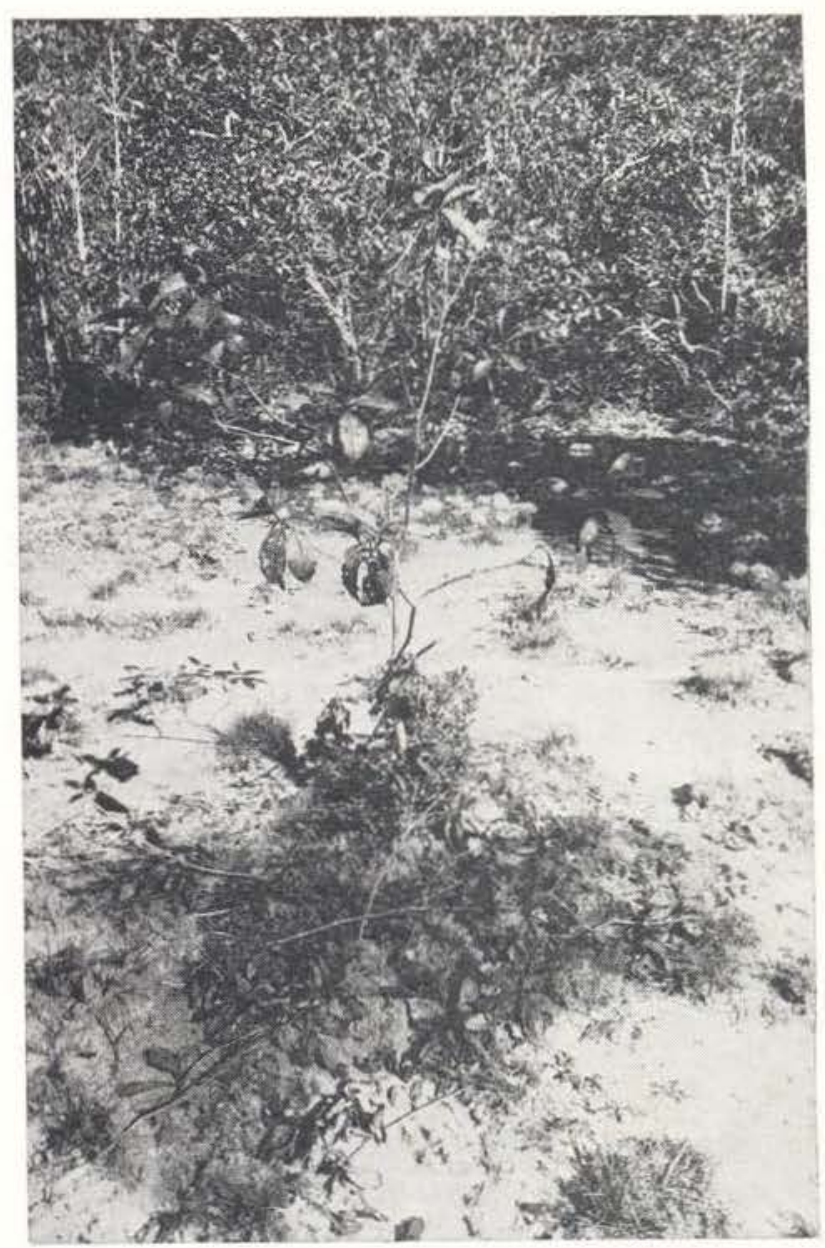

Foto 1. Campina aberta: ilha pequena de Sande. mania hoehnei (Cogn.) Wurdack.

e humus são gradativamente construídos e formam uma manta vegetal característica.

O estabelecimento inicial na campina aberta ocorre por sementes ou por brotamento vegetativo. Entretanto, logo que uma pequena ilha de vegetação é formada, o estabelecimento subseqüente parece ser predominantemente por sementes. Nisto reside o papel decisivo das mantas vegetais que se formam debaixo das plantas pioneiras, pois elas parecem ser os únicos locais onde plântulas de outras espécies estabelecem para ocorrer a colonização subseqüente. Análises do solo feitas em outra campina nas cercanias de Manaus (Falesi, 1970), mostraram que essas mantas vegetais são ricas em sais minerais e matéria orgânica. Contudo, elas são também extremamente ácidas e contém quantidades elevadas de ions tóxicos de alumínio. Estas condições podem bem ser- 
vir para impedir o estabelecimento de outras espécies nas mantas vegetais, o que poderia explicar a alta freqüência de ilhas inteiramente compostas de uma ou outra espécie pioneira. As mantas vegetais podem exercer dupla função para as colonizadoras pioneiras : como fonte de alimento, e proteção contra a invasão de outras espécies. Investigações recentes feitas por pesquisadores do INPA na Reserva de Campina sugerem que substâncias secundárias podem desempenhar um considerável papel na manutenção da vegetação da campina. O pesquisador Dr. Herbert Schubart (comunicação pessoal), por exemplo, encontrou um decréscimo significativo na fauna do solo sob Glycoxylon inophyllum, o principal dominante da Reserva de Campina. Ele emitiu a hipótese de que esta espécie pode produzir substâncias tóxicas capazes de inibir o estabelecimento de espécies competitivas. Esta hipótese está sendo testada por P. Lisbôa e os resultados serão publicados em outro trabalho desta série de estudos da campina.

Com o tempo, outras espécies se estabelecem e as ilhas de vegetação aumentam em tamanho e diversidade. A espécie Ouratea spruceana Engl. parece ser decisiva na transição da campina aberta para a sombreada, pois ela é a única espécie arbórea dominante em ambas $\left({ }^{4}\right)$. Também Protium heptaphyllum (Aubl.) March. é uma importante espécie arbórea de transição, embora não seja rigoros 3 mente dominante na campina. ( $P$. heptaphyllum tem um grau de importância de $4,8 \%$ na campina sberta e de $4,4 \%$ na campina sombreada). Matayba opaca Standley e Talisia cesarina (Benth.) Radlk. são igualmente importantes nesta transição. Estas quatro espécies são as de porte mais alto da campina aberta e, portarito, as ilhas dominadas por elas têm maior quantidade de sombra, provavelmente resultando uma maior diversidade na vegetação. Aqui são novamente encontrados indivíduos de espécies mais características da campina sombreada, como Glycoxylon inophyllum, Clusia aff. columnaris Engl., Hirtella racemosa Lam. var. racemosa, Swartzia dolicopoda Cowan e Pagamea duckei Sandl.

\section{CAMPINA SOMBREADA}

Esta vegetação é mais diversificada estruturalmente do que campina aberta. Em certos lugares é dominada por lotes quase puros de indivíduos de Glycoxylon inophyllum de mesma idade. Mas propriamente, a vegetação consiste de uma diversidade de espécies de tamanhos diferentes que resulta em uma estrutura heterogênea, conforme demonstrado na figura 3. Freqüentemente as árvores são recurvadas e tortas, e o dossel é um emaranhado de ramos tortuosos, entremeando-se com epífitas. As ilhas maiores às vezes são sombreadas por uma enorme Aldina heteropíylla. Esta, por seu turno, a mais alta das espécies da campina, alcançando $7 \mathrm{~m}$ ou mais, possui uma copa dispersa que pode espalhar-se a longa distância, duas vezes mais que sua altura.

Além de Glycoxylon inophyllum e Aldina heterophylla, as outras espécies arbóreas dominantes da campina sombreada são Ouratea spruceana, Swartzia dolicopoda, e Clusia aff. cclumnaris; também são caractersíticas as espécies Maytaba opaca, Talisia cesarina, Protium heptaphyllum e Humiria balsamifera St. Hil. var. floribunda (Mart.) Cuatr. O subarbusto ou arbusto dominante é a Eugenia sp., enquanto que Pagamea duckei, Hirtella racemosa var. racemosa e Tabernaemontana rupicola Benth., são os componentes comuns do estrado inferior. Trepadeiras como Mandevilla uloi K. Schum., Mabea occidentalis Benth., Dcliocarpus spraguei Cheesm., e Heteropterys aff. acutifolia Adr. Juss., são freqüentes.

A composição florística da campina sombreada é mais diversificada do que a da campin? aberta. Nas parcelas de amostragem foram encontradas 23 espécies lenhosas na campina aberta, enquanto que um total de 29 foi encontrado na campina sombreada. Ademais ,a figura 7 mostra que as espécies lenhosas dominantes são um pouco menos importantes na campina sombreada. Nesta, as 6 dominantes atingem um grau de importância de $66,1 \%$; o grau de importância das 6 dominantes da campina aberta é de $81,4 \%$. Esta redução de do-

(4) - Com intenção de discutir um tanto arbitrariamente, consideramos árvores os indivíduos lenhosos com um eixo principal ou caule, com altura aproximada de $5 \mathrm{~m}$. A Ouratea spruceana é portanto uma árvore, enquanto que a Eugenia sp., a única outra espécie dominante na campina aberta e na sombreada, é um arbusto (Eugenia sp. torna-se árvore na campinarana). 


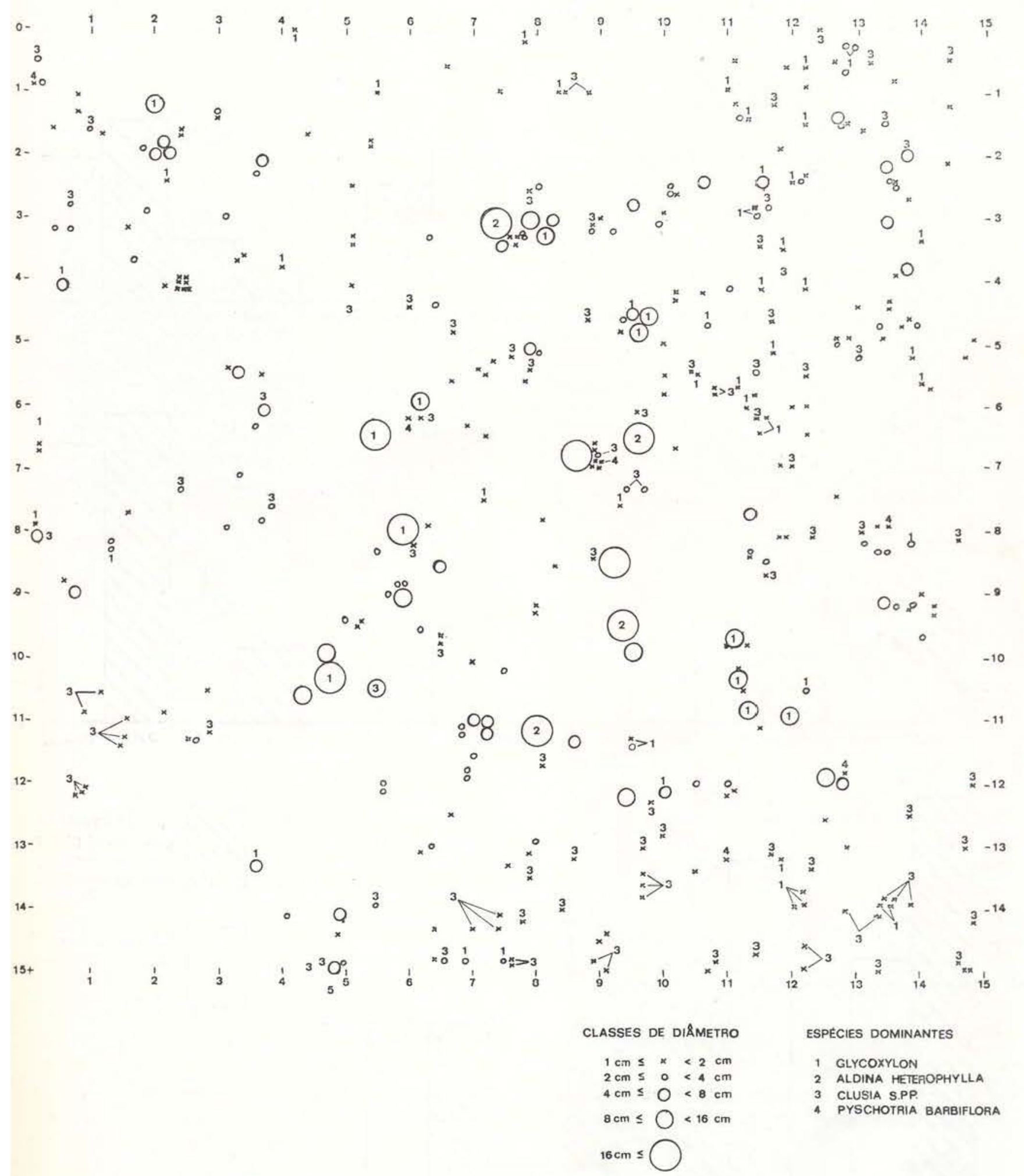

Fig. 6 - Mapa basal de uma área $15 \times 15 \mathrm{~m}$ na campinarana da Reserva Biológica do INPA-SUFRAIMA, com indicação das espécies dominantes. 

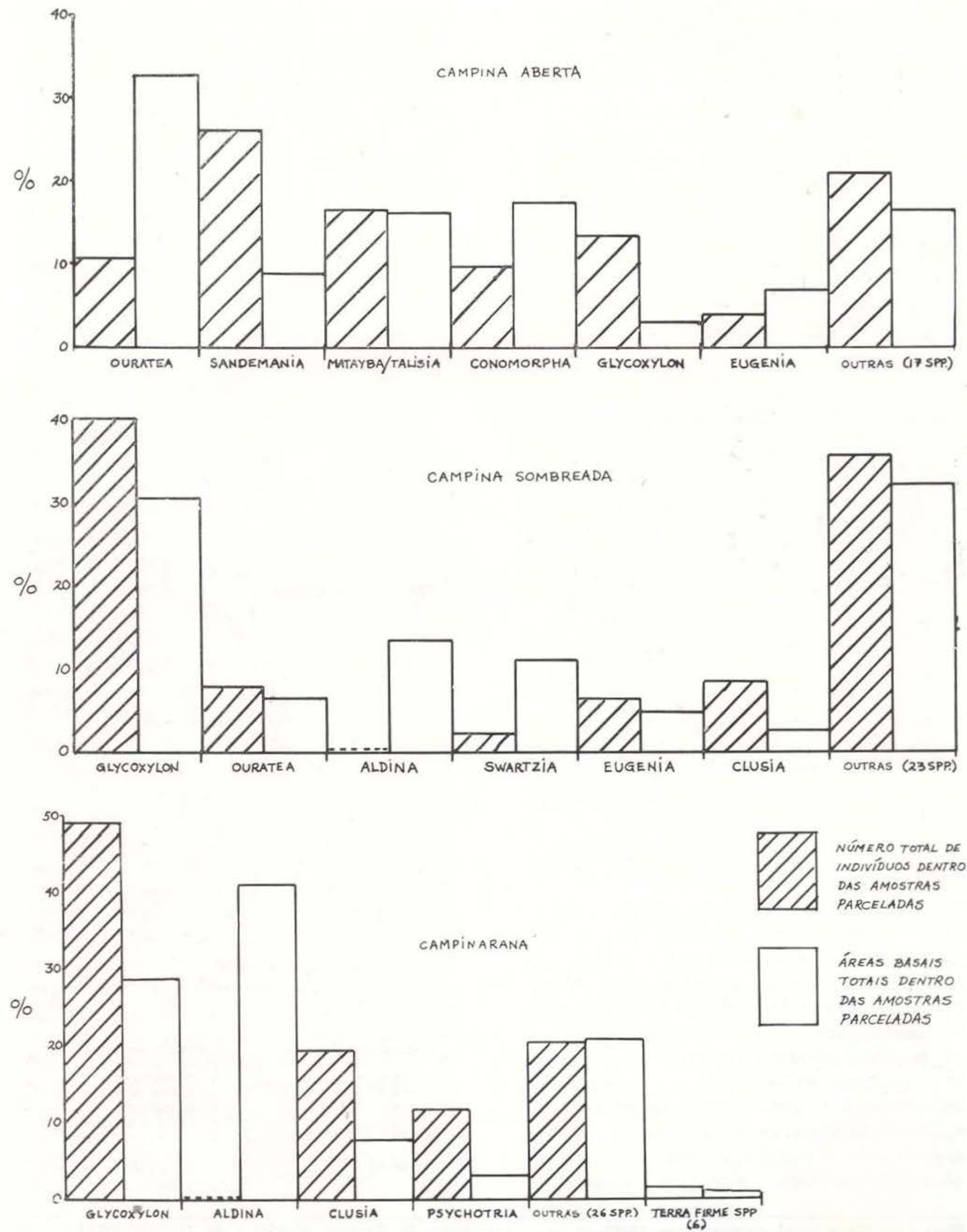

Fig. 7 - Freqüências e áreas das espécies lenhosas dominantas nas amostras parceladas na campina aberta. campina combreada e campinarana da Reserva Biológica do INPA-SUFRAMA. 




Foto 2, Campina aberta: ilha grande dominada por Ouratea spruceana Engl. e Matayba opaca Radlk:

minância na campina sombreada implica numa maior heterogeneidade na composição das espácies, a qual atua como um indicador significante da diversidade aumentada.

\section{CAMPINARANA}

Não há uma divisão definida entre a campina sombreada e a campinarana: as duas se misturam em um "contínuo" sucessional, no qual a estrutura e composição da vegetação gradualmente mudam. Pode-se definir arbitrariamente os dois tipos de vegetação baseando-se na altura do dossel : na campina sombreada as árvores têm menos de $10 \mathrm{~m}$ de altura, enquanto que na campinarana as árvores mais altas freqüentemente ultrapassam $10 \mathrm{~m}$. A vegetação da campinarana é relativamente contí. nua (Figs. 5 e 6); embora as ilhas de árvores maiores possam ainda estar em evidência, elas estão mascaradas pelas áreas intermediá. rias de vegetação mais jovem. Como resuitado desta heterogeneidade no tamanho das árvores o dossel da floresta é extremamente variável em termos de altura e quantidade de sombra que ela fornece.

A transição da campinarana para a mata primária de terra firme é brusca e o limite entre os dois tipos de vegetação é geralmente bem definido. Compreende-se isto simplesmente observando a vegetação do estrato inferici. Um estrato regularmente distinto de subarbustos é encontrado em diversas áreas da campinarana. Quando, porém, entra-se na mata de terra firme, esse estrato vai ficando consideravelmente mais denso e mais contínuo em grande parte de sua área; outrossim, ele

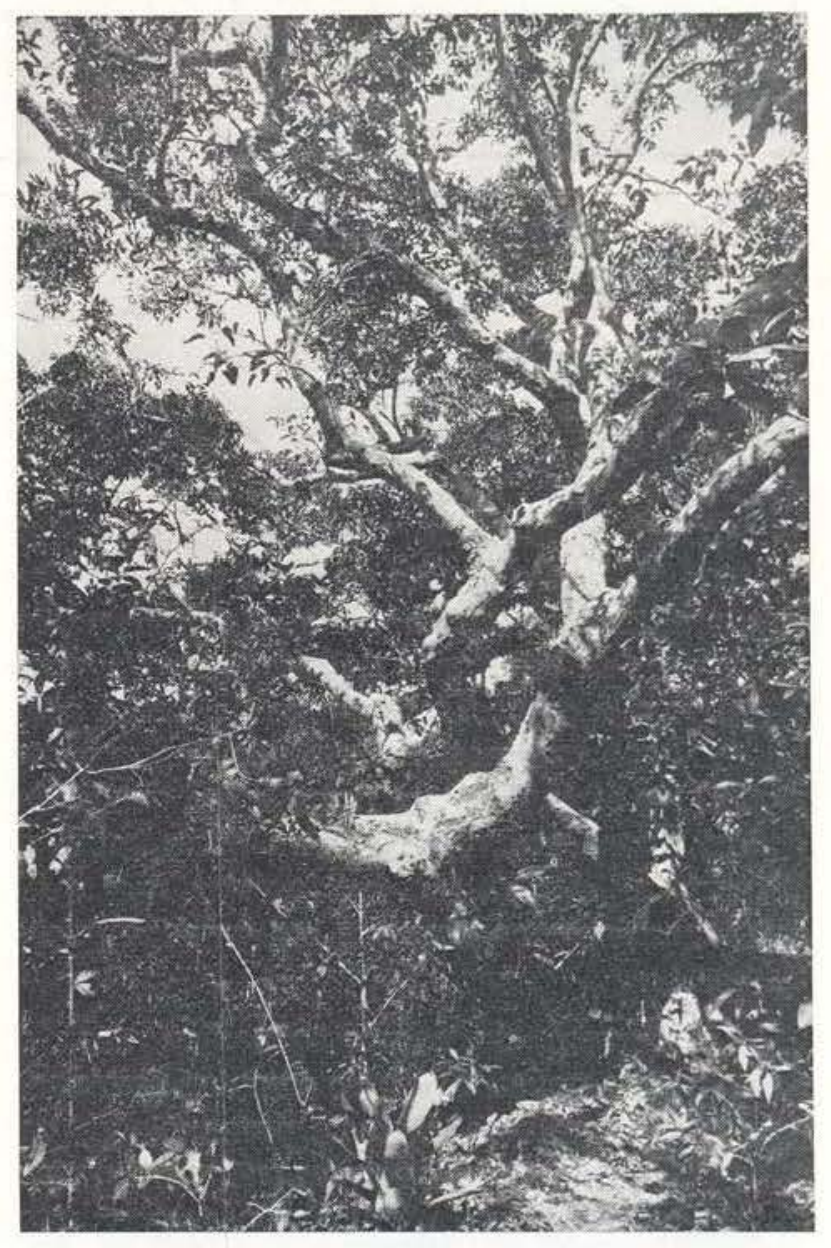

Foto 3. Campina sombreada: Aldina heterophylla Spr. ex Benth. ("macucu"). 


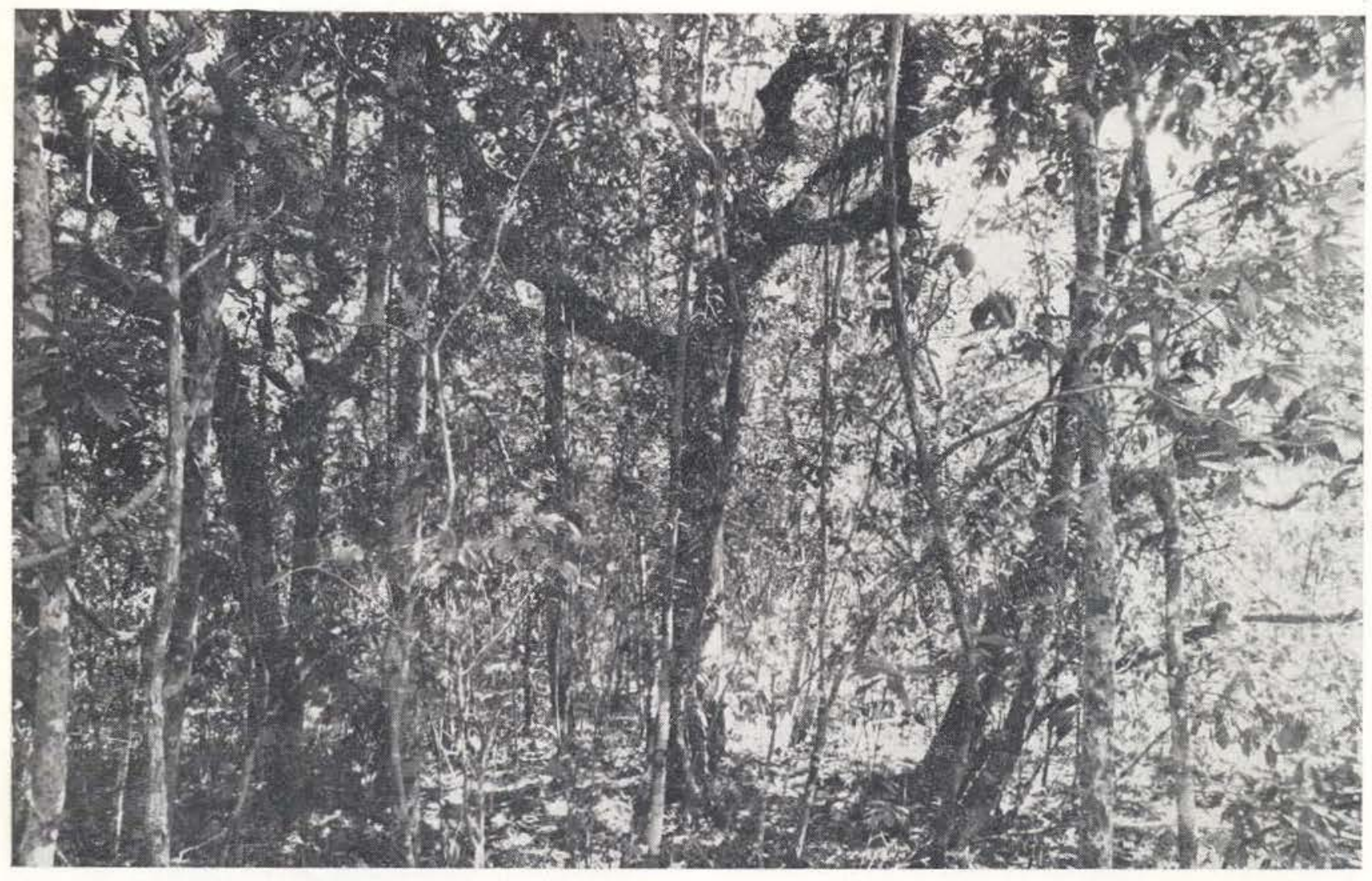

Foto 4. Campinarana.

perde sua identidade distinta, misturando-se com a vegetação mais alta. O repentino aparecimento de palmeiras no estrato inferior é cutra excelente indicação de indícios da mata primária de terra firme. Um terceiro indicador de transição para a mata de terra firme é a redução nítida da liteira no solo. Um aspecto interessante da vegetação da campina e da campınarana é a grande quantidade de liteira acumulada, aparentemente resistindo à decomposição. Na mata de terra firme e em quase todas as matas tropicais de terra firme baixa, a decomposiçáo atua tão rapidamente que a liteirs raramente se acumula em grandes quantidades.

Em termos de composição florística, a campinarana pouco difere da campina sombreada. De fato, alterações mais pronunciadas na composição flcrística ocorrem entre a campina aberta e a sombreada. A figura 4 apresenta as plantas dominantes da campinarana; apenas Psychotria barbiflora DC. não é também uma espécie dominante na campina sombreada. A dominância total, que declina na campina sombreada, mais uma vez aumenta na campinarana. Nestas, as 4 dominantes lenhosas possuem um grau de importância de $79,4 \%$, significativamente mais elevado do que o grau de $66,1 \%$ para as 6 dominantes da campina sombreada. Este aumento de dominância implica numa heterogeneidade mais baixa da composição específica, que tende a sugerir um decréscimo na diversidade total da campinarana. Entretanto, quando se caminha da campina sombreada para a campinarana, nota-se um aumento no número total de espécies (o total real desse aumento não pode ser calculado enquanto as áreas de amostragem da campinarana e da campina sombreada não forem iguais). Uma elevação no número total de espécies combinada com a heterogeneidade mais baixa da composição florística, sugerem que a diversidade total da campinarana está se aproximando do equilibrio.

Odum (1971) estabelece que, quando a sucessão ocorre entre dois tipos de vegetação, 
um nivelamento de diversidade sugere a proximidade de uma condição de clímax, na qual a composição da vegetação de uma dada área perman€ce em equilíbrio por muito tempo. De fato, a vegetação da campinarana parece estar em clímax. Esta conclusão é apoiada na observação de que o estabelecimento de espécies da mata de terra firme praticamente não existe na campinarana, conforme demonstrado na íigura 7. De acordo com o que foi discutido anteriormente, a alteração brusca da campinarana para a mata de terra firme indica uma discontinuidade definida entre esses dois tipos de vegetação, é a evidência adicional de que a sucessão atingiu o clímax na campinarana.

\section{CONCLUSÃo}

Embora a vegetação da campina e da campinarana forme uma série contínua, a análise anterior mostra a necessidade de dividí-la em três tipos ou subtipos: campina aberta, campina sombreada e campinarana. Especialmente com referência à campina aberta e à campina sombreada, as definições fornecidas no presente trabalho são um tanto arbitrárias; contudo, elas podem corresponder bem às mudanças significativas na estrutura e composição da vegetação que ocorrem entre esses dois subtipos. Falta-nos, porém, uma análise fitossociológica quantitativa que poderia fornecer definições mais exatas para esses dois termos, do que os apresentados neste trabalho. Para o momento, devemos limitar o uso desses termos para a campina estudada neste trabalho. Num próximo trabalho, dois dos autores (A. B. Anderson \& G. T. Prance) apresentarão um estudo comparativo da vegetação lenhosa de três campinas da região do rio $\mathrm{Ne}$ gro, no qual esperamos determinar se os termos apresentados no presente trabalho tem aplicação mais ampla. Observações preliminares sugerem que esses termos na verdade tem um emprego mais amplo, embora os parâmetros precisos de cada subtipo possam variar de campina para campina.

O tema da sucessão tem sido uma constante meia voz neste estudo da vegetação da campina e da campinarana. O principal autor (A. B. A.) pretende examinar mais detalha- damente os aspectos da sucessão vegetacional da campina e da campinarana num futuro trabalho.

\section{AgRAdeCIMENTOS}

Agradecemos aos Srs. José F. Ramos e Osmarino P. Monteiro, pelo auxílio no campo; Sra. Osmarina Santos de Oliveira, pela preparação das tabelas e diversos aspectos datilo. gráficos; Sra. Léa Carreira, pela ajuda na preparação de material e da chave; Sra. Anne Prance e Srta. Elza Suely Guedes de Carvalho, pela ajuda na preparação das figuras; Dr. J. H. Kirkbride, Jr. e Sra. C. Garcia-Kirkbride, pelas identificações feitas no herbário de New York Botanical Garden; Sras. Marlene F. da Silva e Regina Lisboa pela leitura e correção do trabalho.

As pesquisas do autor Anthony B. Anderson foram realiazdas com o apoio de uma bolsa do Thomas J. Watson Foundation, Providence R.I., EE.UU.

\section{SUMMARY}

Throughout Northern Amazonia, and especially in the Rio Negro region, scattered white sand soils and their associated vegetation, referred to as campinas amazonicas, may have considerable influence on the overall ecology of blackwater river systems. This paper presents a description of the woody vegetation of one campina and its associated campina forest (campinarana), in Central Amazonia at $\mathrm{km} 62$ of the Manaus-Caracaraí road.

The term "campina" is here used to describe a vegetational type which occurs in readily discernible clusters, forming islands or peninsulas which are surrounded by or adjacent to relatively open areas of bare sandy soil. The tallest campina trees never reach $10 \mathrm{~m}$ in height, and the canopy (where one exists) is rarely continuous over a large area. The authors believe that the campina vegetation is best understood by dividing it into two distinct sub-types: "sun campina" (campina aberta) and "shade campina" (campina sombreada). Sun campina consists of islands of vegetation, each island with an area smaller that $1 \mathrm{~m}^{2}$, over which the canopy cover is less than $50 \%$. Shade campina refers to islands or areas of vegetation larger than $1 \mathrm{~m}^{2}$, ove: which the canopy cover exceeds $50 \%$. These latter definitions are somewhat arbitrary and, as we lack a quantitative phytosociological, analysis of campina, vegetation, they should be considered tentative. However, within the particular campina under study, they do correspond rather 
well to areas of vegetation with significantly distinct structure and composition.

The term "campina forest" is applied here to a a vegetational type which occurs adjacent to the campina and on similar white sandy soil. The vegetation of the campina forest is generally taller than that of the campina, with individuals often exceeding $10 \mathrm{~m}$ in height. Within the campina forest, the vegetation is likewise more continuous: isolated clusters of taller trees may still be discernible, but the intervening expanses of sand here become colonized by younger trees and shrubs.

The vegetational structure of the sun campina, shade campina, and campina forest are examined in detail. These three vegetational types or sub-types form a successional sequence which proceeds from sun campina to shade campina to campina forest. On the basis of vegetational evidence, the authors conclude that the campina forest represents a successional climax.

\section{BIBLIOGRAFIA CITADA}

BRAgA, M.N. \& BRAgA, P.I.S.

1975 - Estudos ecológicos da campina da Reserva Biológica INPA-SUFRAMA (Manaus-Caracaraí, $\mathrm{Km}$ 62) Acta Amazônica, Manaus, 5(3):

DUCKE, A. \& BLACK, G.A.

1954 - Notas sobre a fitogeografia da Amazônia Brasileira. Boletim Técnico do IAN, Belém, 29:1-62.

FAlesí, I.C.

1970 - Os solos da área Cacau-Pirêra-Manacapurú. Inst. Pesq. Exp. Agrop. do Norte, Série: Solos da Amazônia, 2(3):1-198.

1971 - Solos do distrito agropecuário da SuFrama. Inst. Pesq. Exp. Agrop. Amazo. Occ., Série: Solos, 1(1):1-99.
JANZEN, D.H.

1974 - Tropical blackwater rivers, animals and mast fruiting by the Dipterocarpaceae. Biotropica, 6(2):69-103.

KLINGE, H.

1965 - Podzol soils in the Amazon Basin. Jour. Soil Sc., 16(1):95-103

LISBOA, P.L.

1975 - Observações sobre a vegetação da campina de areia branca na Amazônia, incluindo revisão bibliográfica. Acta Ama. zonica, Manaus, 5(3):

ODUM, H.P.

1971 - Fundamentals of Ecology, 3. ed. Philadelphia, W. B. Saunders

PIRES, J.M. \& RODRIGUES, J.S.

1964 - Sobre a flora das caatingas do Rio Negro. In: Anais do 13. Congresso de Botânica do Brasil, p. 242-262.

Prance, G.T.; Rodrigues, W.A. \& Sillva, M.F.

1975 - Inventário florestal de um hectare de mata da terra firme, $\mathrm{Km} 30$ da Estrada Manaus-Itacoatiara (no prelo).

Ribeiro, M.N.G. \& SANTos, A. Dos

1975 - Observações climatológicas no Ecossistema Campina Amazônica. Acta Amazo. nica, Manaus, 5(2) : 183-189

RICHARDS, P.W.

1952 - The Tropical Rain Forest. Cambridge Univ. Press.

RODRIGUES, W.A.

1961 - Aspectos fitosociológicos das caatingas do Rio Negro. Bol. Mus. Par. Emílio Goeldi, N.S.: Botânica, 15:1-41.

SPRUCE, R.

1908 - Notes of a Botanist on the Amazon and Andes. London, A. R. Wallace.

TAKELICHI, $M$.

1960 - A estructura da vegetação na Amazônia. III. A mata da campina na região do Rio Negro. Bol. Mus. Par. Emílio Goeldi, N.S.: Botânica, 8:1-13. 


\section{ANEXO 1. CHAVE PARA A SEPARAÇÃO DAS ESPÉCIES NA \\ CAMPINA DA RESERVA BIOLÓGICA DO INPA-SLFRAMA}

1. Planta ereta.

2. Folhas simples.

3. Folhas claramente alternas.

4. Folhas translúcido-pontuadas.

5. Folhas fortemente aromáticas.

5. Folhas não aromáticas.

4. Folhas não translúcido-pontuadas.

6. Folhas lineares ou linear-lanceoladas, pubérulas por toda a parte.

6. Folhas não linear nem linear-lance.oladas e não pubérulas.

7. Ápices das folhas agudos ou acuminados.

8. Ramos novos e pecíolos pubérulos.

8. Ramos novos e pecíolos glabros.

7. Apices das folhas obtusos ou retusus.

9. Estípulas presentes e persistentes.

9. Estípulas ausentes ou não persistentes.

10. Folhas com nervação secundária fina.

10. Folhas com nervação secundária saliente.

3. Folhas opostas, verticiladas ou espiraladas no ápice dos ramos e não claramente alternas.

11. Látex presente.

12. Folhas translúcido-pontuadas.

12. Folhas não translúcido-pontuadas.

13. Folhas com nervação proeminente.

13. Folhas com nervação fina.

14. Casca brilhantemente coiorida e que se descasca por si.

Annona nitida Mart.

(Annonareae). Ocasional

Ouratea spruceana Engl.

(Ochnaceae). Comum.

Vernonia grisea Baker

(Compositae). Ocasional

Hirtella racemosa Lam. var. racemosa

(Chrysobalanaceae) Comum.

Doliocarpus spraguei Cheesm.

(Dilleniaceae). Ocasional.

Erythroxylum sp.

(Erythroxylaceae). Ocasional.

Humiria balsamifera St. Hil. var floribunda (Mart.)

Cuatr. (Humiriaceae). Ocasional.

Dendrobangia sp.

(Icacinaceae). Rara.

Tabernaemontana rupicola

Benth. (Apocynaceae). Comum.

Mandevilla ulei K. Schum

(Apocynaceae). Comum.

Glycoxylon inophyllum (Mart. ex Miq.) Ducke (Sapotaceae). Comum. 
ANEXO I. Chave para a Separação das Espécies... (continuação)

14. Casca não brilhantemente colorida e não se descasca.

15. Folhas agrupadas em espiral no ápice dos ramos.

15. Folhas opostas e não agrupadas em espiral no ápice dos ramos.

16. Raizes suportes presentes na base do caule; ápice das folhas agudo.

16. Raízes suportes ausentes na base do caulc; ápice das folhas obtuso.

11. Látex ausente.

17. Estípulas interpeciolares presentes

18. Folhas lineares.

18. Folhas não lineares.

19. Superfície das folhas semi-plicada (bolhada)

19. Superfície das folhas não semi-plicada.

20. Folhas com nervação secundária saliente, principalmente na face inferior.

21. Ramos novos, pecíolos e lâminas pubérulos.

21. Ramos novos, pecíolos e lâminas glabros.

22. Folhas de base aguda.

22. Folhas de base obtusa.

20. Folhas com nervação secundária não saliente.

17. Estípulas ausentes.

23. Folhas com mais de uma nervura principal.

24. Folhas pubescentes.

24. Folhas glabras.
Manilkara amazonica (Huber)

Standl. (Sapotaceae). Ocasional.

Clusia aff. columnaris Engl. (Guttiferae). Comum.

Clusia cf. nemorosa G.F.W. Meyer (Guttiferae). Rara.

Borreria capitata var. tenella

(H.B.K.) Steyerm. (Rubiaceae).

Ocasional.

Pagamea duckei Standl.

(Rubiaceae). Comum.

Psychotria barbiflora DC.

(Rubiaceae). Rara.

Falicourea nitidella (M. Arg.)

Standl. (Rubiaceae). Ocasional.

Palicourea cf. Iupulina Benth. subsp. rhodoleuca (Mull. Arg.) Steyerm. var. maypurensis (Humb. \& Bonp. ex R. \& S.) Steyerm. sens! Steyerm. Rubiaceae). Ocasional.

? Duroia sp. (Rubiaceae). Rara.

Sandemania hoehnei (Cogn.) Wurdack (Melastomataceae). Comum.

Miconia lepidota DC.

'Melastomataceae). Ocasional. 
23. Folhas com apenas uma nervura principal.

25. Pecíolos extremamente curtos de modo que as folhas frequentemente parecem sésseis; folhas de base cordada.

25. Pecíolos não extremamente curtos; foihas com base não cordada.

26. Folhas transiúcido-pontuadas.

27. Folhas espiraladas, dispostas no ápice dos ramos.

27. Folhas não espiraladas.

28. Folhas decussadas.

28. Folhas não decussadas.

29. Ápice das folhas bruscamente acuminado.

29. Ápice das folhas agudo.

26. Folhas não translúcido-pontuadas.

30. Ápice das folhas agudo.

30. Ápice das folhas retuso.

2. Folhas compostas.

31. Folhas imparipinadas.

32. Plantas fortemente aromáticas.

32. Plantas não fortemente aromáticas.

33. Folíolos com o ápice retuso.

33. Folíolos com o ápice não retuso.

34. Ramos jovens com lenticelas; folhas sem pecíolos alados; folíolos com o ápice agudo ou acuminado, mais nunca apiculado.

34. Ramos novos sem lenticelas; folhas freqüentemente com pecíolos alados; folíolos com o ápice mais ou menos apiculado.

31. Folhas paripinadas.

35. Folhas com dois ou ocasionalmente quatro folíolos.
Mouriri nervosa Pilg.

(Melastomataceae). Rara.

Conomorpha cf. grandiflora

Mez (Myrsinaceae). Comum

Eugenia sp. (Myrtaceae). Comum.

Myrcia servata McVaugh

(Myrtaceae). Rara.

Eugenia patrishi Vahl

(Myrtaceae). Rara.

Heteripterys aff. acutifolia

Adr. Juss. (Malphigiaceae). Rara.

Qualea retusa Spruce ex Warm.

(Vichysiaceae). Rara.

Protium heptaphyllum (Aubl.)

March. (Burseraceae). Comum.

Ormosia costulata (Miq.) Kleinh.

(Leguminosae). Ocasional.

Aldina heteriphylla Spr. ex Benth (Leguminosae). Ocasional.

Swartzia dilicopoda Cowan

(Leguminosae). Ocasional.

Macrolobium arenarium Ducke (Leguminosae). Rara. 
ANEXO I. Chave para a Separação das Espécies... (continuação)

35. Folhas com seis ou mais foliolos.

36. Folíolos eretos.

36. Folíolos reflexos.

1. Trepadeira, epífita ou hemipasita.

37. Látex presente.

38. Folhas opostas.

38. Folhas alternas.

37. Látex ausente.

39. Plantas hemiparasitas; folhas opaco-pontuadas.

40. Folhas lanceoladas com o ápice acuminado.

40. Folhas oblanceoladas, com o ápice obtuso ou retuso.

39. Plantas não hemiparasitas; folhas sem pontuações.

41. Epifitas; folhas espessas, carnosas.

42. Folhas espiraladas.

42. Folhas não espiraladas.

43. Folhas opostas ou verticiladas.

43. Folhas alternas.

41. Trepadeiras; folhas finas, não carnosas.

44. Gavinhas presentes.

44. Gavinhas ausentes.

45. Folhas opostas.

46. Caule com nó intumecido na região interpeciolar.

46. Caule sem nó intumescido na região interpeciolar.

47. Ramos novos com lenticelas.

47. Ramos novos sem lenticelas.

Phthirusa rufa (Mart.) Eichl.

(Loranthaceae). Ocasional.

Phthirusa micrantha Eichl.

(Loranthaceae). Ocasional.

Mandevilla ulei K. Schum.

(Apocynaceae). Comum.

Mabea occidentalis Benth.

(Euphorbiaceae). Comum.

Codonanthopsis aggregata

(Mart.) Hoehne

(Gesneriaceae). Rara.

Codonanthe sp. (Gesneriaceae). Rara.

Codonanthe aff. crassifolia (Focke) Morton (Gesneriaceae). Rara.

Passiflora faroana Harms

(Passifloraceae). Ocosional.

Gnetum pasiculatum Spr.

(Gnetaceae). Rara.

Heteropterys aff. acutifolia Adr. Juss. (Malpighiaceae). Rara.

Mikania roraimensis Robinson (Compositae). Ocasional.

45. Folhas alternas.

Doliocarpus spraguei Cheesm. (Dilleniaceae). Ocasional.

Anderson et al. 